\title{
Pharmacophore Identification for Peroxisome Proliferator-Activated Receptor Gamma Agonists
}

\author{
Young-sik Sohn, Yuno Lee, Chanin Park, Swan Hwang, Songmi Kim, Ayoung Baek, Minky Son, Jung-Keun Suh, \\ Hyong-Ha Kim, ${ }^{, * *}$ and Keun Woo Lee
}

\author{
Division of Applied Life Science (BK21 Program), Plant Molecular Biology and Biotechnology Research Center (PMBBRC), \\ Gyeongsang National University (GNU), Jinju 660-701, Korea. ${ }^{*} E-m a i l: k w l e e @ g n u . a c . k r$ \\ ${ }^{\dagger}$ Bio Computing Major, Korean German Institute of Technology, Seoul 157-033, Korea \\ ${ }^{\ddagger}$ Division of Quality of Life, Center of Bioanalysis, Korea Research Institute of Standards and Science (KRISS), \\ Daejeon 305-340, Korea
}

Received October 8, 2010, Accepted November 15, 2010

\begin{abstract}
Peroxisome proliferator-activated receptors (PPARs) are members of nuclear receptors and their activation induces regulation of fatty acid storage and glucose metabolism. Therefore, the PPAR $\gamma$ is a major target for the treatment of type 2 diabetes mellitus. In order to generate pharmacophore model, 1080 known agonists database was constructed and a training set was selected. The Hypo 7, selected from 10 hypotheses, contains four features: three hydrogen-bond acceptors (HBA) and one general hydrophobic (HY). This pharmacophore model was validated by using 862 test set compounds with a correlation coefficient of 0.903 between actual and estimated activity. Secondly, CatScramble method was used to verify the model. Hence, the validated Hypo 7 was utilized for searching new lead compounds over 238,819 and 54,620 chemical structures in NCI and Maybridge database, respectively. Then the leads were selected by screening based on the pharmacophore model, predictive activity, and Lipinski's rules. Candidates were obtained and subsequently the binding affinities to PPAR $\gamma$ were investigated by the molecular docking simulations. Finally the best two compounds were presented and would be useful to treat type 2 diabetes.
\end{abstract}

Key Words: Peroxisome proliferator activated receptor $\gamma(\operatorname{PPAR} \gamma)$, Computer-aided drug design, Pharmacophore model, Virtual screening, Molecular docking

\section{Introduction}

Peroxisome proliferator-activated receptor $\gamma(\operatorname{PPAR} \gamma)$, which regulates gene expression, is the third component of broader nuclear receptor superfamily and is a modular structure including some functional domains. The receptor functions as heterodimer with retinoid X receptor (RXR) which enhances DNA-binding and then regulates DNA transcription by binding to defined nucleotide sequences (peroxisome proliferator response element, PPRE) in the promoter region of target genes. ${ }^{1-4}$ Several cofactors (coactivators or corepressors) mediate the ability of nuclear receptors to stimulate or repress the transcription process. ${ }^{5}$ When the mutant type of PPAR $\gamma$ binds with RXR, corepressor constitutes complex stick to the heterodimer. Then, basal transcription factors (BFTs) are not binding. When the normal type of PPAR $\gamma$ binds with RXR, co-activator forms complex stick to the heterodimer. After that, BTFs are binding and many functions are carried out. ${ }^{6}$

PPAR $\gamma$ consists of four domains including transcription regulation domain, DNA binding domain, hinge domain, and ligand binding domain. ${ }^{7,8}$ Two key sites are known for the regulating transcription: K107 for sumoylation, and S112 for phosphorylation. If phosphorylation is working, mitogen-activated protein kinase (MAPK) mediated the reaction. ${ }^{8}$ PPAR $\gamma$ contains six different forms in human, namely: PPAR $\gamma 1$ (widespread expression and expressed in all tissues, including heart, muscle, colon, kidney, pancreas, and spleen), PPAR $\gamma 2$ (additional 28 amino acids at its N-terminus), PPAR $\gamma 3$ (expressed in macrophages, large intestine, white adipose tissue), PPAR $\gamma 4$,

\section{PPAR $\gamma 5$, and PPAR $\gamma 7 .^{3,9-12}$}

Type 2 diabetes is a metabolic disease that is occurred by high levels of glucose in the blood. Activated PPAR $\gamma$ which takes a place in adipose tissue and macrophages promotes fat cell differentiation and regulates fatty acid storage and glucose metabolism by affecting related genes. Therefore, the PPAR $\gamma$ is a major drug target for the treatment of type 2 diabetes mellitus. Although some naturally occurring molecules such as eicosnoids and polyunsaturated fatty acids are capable of activating this receptor, artificial ligands have more potentialities as agonists of PPAR $\gamma$. Thus, the goal of the present study is to generate a meaningful pharmacophore model for PPAR $\gamma$ agonist which treats type 2 diabetes mellitus. ${ }^{13}$

The pharmacophore modeling was employed to present meaningful information for developing new agonist candidates targeting the PPAR $\gamma$. The most meaningful pharmacophore was selected along with developed protocols and then it was well validated by CatScramble and test set. New lead compounds which have comparable structures were retrieved from database. New lead compounds from chemical database were selected and they screened by our pharmacophore model and drug-like properties. Finally, molecular docking studies were performed to calculate reasonable interactions for the final screened molecules.

\section{Methods}

Data Collection and Training Set Selection. The structure and biological activity data for 2110 PPAR agonists were col- 
1

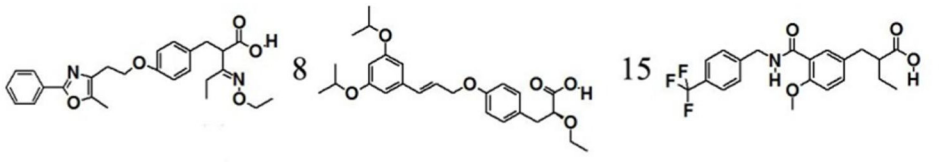

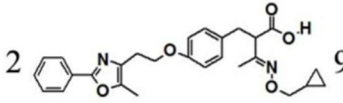

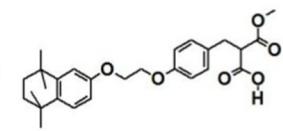

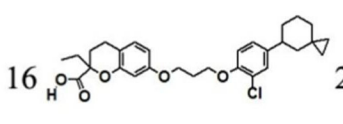
23 22

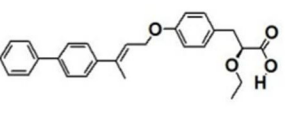<smiles>[134IH]</smiles>

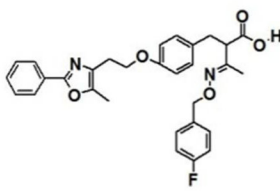

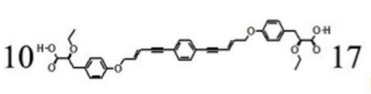

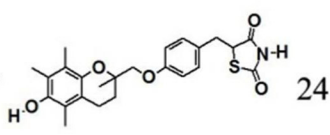
24

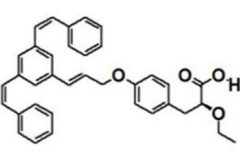<smiles>CCNC(=O)C(C)CC</smiles>

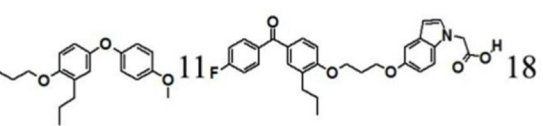

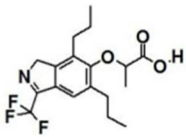

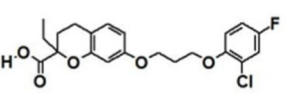

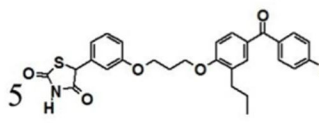

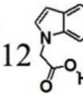

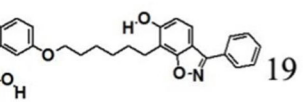

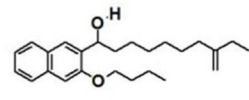<smiles>O=C(O)C(=O)OCC1CCC(OCN(Cc2ccccc2)c2ccccc2)C1</smiles>

6

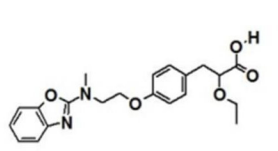<smiles>[131IH]</smiles>

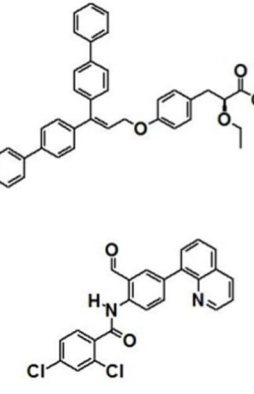

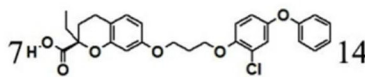<smiles>O=C(NCCCc1ccccc1)OCc1cccc(O)c1</smiles><smiles>CN(C)C(=O)c1ccc(C=Cc2cccn2C)cc1O</smiles>

Figure 1. Chemical structures of 26 compounds in training set.

lected from the published journals. ${ }^{14-31}$ Finally, 1080 compounds were selected for the PPAR $\gamma$ agonist database after filtering process. The next step is the selection of training set and the following five general guidelines were applied for the selection. (i) The training set contains at least 16 molecules to avoid any fortunate correlation. (ii) The range of activity should be 4 - 5 orders of magnitude. (iii) The molecules which have clear, brief structural information should be selected. (iv) To generate a reasonable pharmacophore model, the most active molecules which offer reliable chemical features should be included. (v) The reason of containing inactive molecules is to avoid steric hindrance. ${ }^{32}$ And then, based on the activity the training set molecules were classified into four groups of highly active, moderately active, least active and inactive one. As the result, the 26 PPAR $\gamma$ agonists were finally selected as the training set to represent structural variety and activity ranging from $0.1 \mathrm{nM}$ to $3000 \mathrm{nM}$ with $\mathrm{EC}_{50}$ (Fig. 1). The Best Conformational Analysis method and Poling Algorithm were employed with an energy constraint of $20 \mathrm{kcal} / \mathrm{mol}$ to generate the maximum of 250 conformations for each training set compound. ${ }^{33}$
Pharmacophore Hypotheses Generation by HypoGen. All 10 pharmacophore hypotheses were generated using HypoGen module in CATALYST 4.10. ${ }^{34}$ In this procedure, the uncertainty was used as default value 3 , which means the ratio of the uncertainty range of measured biological activity against actual activity for each compound. To specify the minimum distance between feature points, spacing parameter was set to 297 picometers $(2.97 \AA)$ as default. After then, the best model which contains important chemical features was selected as PPAR $\gamma$ agonist from the result of 10 hypotheses. The ranges of standard costs are divided by three. First, the difference of null cost and fixed cost is between 60 and 70 bits. Second, the total cost must near to the fixed cost. Third, configuration cost must be less than $17 .^{32}$ All 10 hypotheses were allowed by above ranges. Finally, Hypo 7 was selected as the best model after considering of following two validations that described in next panel.

Test Set and CatScramble Validations of Pharmacophore Hypothesis. All 10 hypotheses are validated by the test set method and the CatScramble method. ${ }^{35}$ The 862 molecules were taken as test set from the in-house database by the same rule and 
Table 1. Information of pharmacophore hypotheses and cost values

\begin{tabular}{ccccccc}
\hline \multirow{2}{*}{ Hypo No. } & \multirow{2}{*}{ Features $^{a}$} & \multicolumn{3}{c}{ Training set $^{2}$ Test set } \\
\cline { 3 - 6 } & & Total cost $^{b}$ & $\Delta$ Cost $^{c}$ & RMSD & Correlation (r) & Correlation (r) \\
\hline 1 & AAAY & 106.034 & 61.978 & 0.727 & 0.956 & 0.485 \\
2 & AAAY & 106.952 & 61.060 & 0.776 & 0.950 & 0.748 \\
3 & AAAY & 107.665 & 60.347 & 0.812 & 0.945 & 0.471 \\
4 & AAYY & 107.840 & 60.172 & 0.815 & 0.944 & 0.493 \\
5 & AAYY & 107.870 & 60.142 & 0.818 & 0.944 & 0.451 \\
6 & AAAY & 108.007 & 60.005 & 0.816 & 0.944 & 0.563 \\
7 & AAAY & 108.297 & 59.715 & 0.839 & 0.941 & 0.903 \\
8 & AAYY & 108.884 & 59.128 & 0.861 & 0.938 & 0.523 \\
9 & AAAY & 109.816 & 58.196 & 0.904 & 0.931 & 0.526 \\
10 & AAAY & 111.464 & 56.548 & 0.965 & 0.921 & 0.741 \\
\hline
\end{tabular}

${ }^{a} \mathrm{~A}$, hydrogen-bond acceptor; Y, general hydrophobic. ${ }^{b}$ Null cost for 168.012 bits, fixed cost for 99.086 bits, configuration cost for 10.507 bits; Total cost which is the standard for estimate pharmacophore model has to close to fixed cost. ${ }^{c} \Delta$ Cost indicates the difference of null cost and total cost.

way of selecting training set, and were screened by Hypo7. The statistical validation of Hypo 7 was performed by Fischer's randomization test, using CatScramble. ${ }^{33}$ Namely, the chemical structures and the actual activities in training set were randomly mixed each other. If some correlation values between the structures and activity are closed to our model, the best pharmacophore model was obtained by chance. From this validation, 19 spread-sheets were generated by considering $95 \%$ confidence level. $^{36}$

Database Screening through the Pharmacophore and Druglike Properties. After the validation, the most suitable compounds can be screened by 4 features of Hypo 7. The new lead compounds were obtained by screening of Maybridge database and NCI database. The virtual screening was performed by using Best Flexible Search Databases/Spread Sheets which is able to change the molecule conformation. ${ }^{37}$ In this step, the molecules are geometrically fitted with pharmacophore features and then generate the estimated activities.

A drug must have intestinal permeability and absorption for react in the body. The information was offered by Molinspiration online database. ${ }^{38}$ The Lipinski's rule-of-five proposes five standards for the drug. (i) The number of $\log P<5$. (ii) The number of molecular weight $<500$. (iii) The number of $H$-bond donor $<5$. (iv) The number of H-bond acceptor $<10$. (v) The number of rotatable bond $<10$. $^{39}$

Molecular Docking Calculation. Molecular docking calculations of agonists into the active site of the PPAR $\gamma$ crystal structure (PDB ID: 2ATH) were performed by GOLD 3.0.1 program (Genetic Optimization for Ligand Docking) ${ }^{40}$ to compare with the pharmacophore mapping. The program uses a genetic algorithm for flexible protein-ligand docking. Scoring functions containing GoldScore, ChemScore and User-defined score are available and GoldScore was selected among the three scores for this study. Centroid, the center of known ligand binding into the active site of PPAR $\gamma$, is defined as active site around $10 \AA{ }^{37}$ We allowed such options 'Ring-NHR and RingNR1R2 of flip all planar R-NR1R2 in ligand flexibility' and ' $-(\mathrm{O}=\mathrm{C})-\mathrm{OH}$ of flip protonated carboxylic acids' in GOLD program. Finally, the search efficiency in genetic algorithm settings regulated as $100 \%$.

\section{Results and Discussions}

Pharmacophore Hypothesis Generation and Selection from Top 10 Hypotheses. A set of 10 pharmacophore hypotheses was generated using the data from the 26 training set compounds. The HypoGen in CATALYST was performed to analyze the costs such as 'fixed cost' which symbolizes the simple model that fits all data perfect and 'null cost' which presumes that there is no statistically relationship in the dataset. The more difference between null cost and fixed cost, the more reasonable pharmacophore hypothesis and the total cost of the hypothesis should be close to the fixed cost. A difference of cost greater than 60 bits is a superb chance that the model represents a true correlation and a value of 40 - 60 bits may suggest $75-90 \%$ probability of correlation. ${ }^{33}$ Therefore, a set of the best pharmacophore hypotheses was selected by some standard values like high cost difference (null cost - fixed cost), low error cost, low root mean square deviation (RMSD) and high correlation coefficient. ${ }^{32}$ All the information for the pharmacophore features, cost values, RMSD, and correlation coefficient ( $\mathrm{r}$ ) of the hypotheses are listed along with test set correlation (Table 1). In the table, although Hypol is the most significant hypothesis, Hypo 7 pharmacophore model was selected by the best test set correlation (r). Because all values were similar among the pharmacophore hypotheses and the Hypo 7 showed the highest test set correlation (0.903). Configuration cost, meaning the complication of the hypotheses space to explore, is a constant value preferably less than $17 .^{36,37}$ The null cost, the fixed cost, and the configuration cost value of the 10 hypotheses were $168.012,99.0865$, and 10.5078 , respectively. Seven hypotheses including Hypo 7 have the same 4 features of three hydrogen-bond acceptors (HBA) and one general hydrophobic (HY), while the other 3 hypotheses are slightly different with one hydrogen-bond acceptor replacing one general hydrophobic group (Table 1). Three-dimensional (3D) pharmacophore model of Hypo 7 was represented with distances between the four features (Fig. 2).

All compounds in present study were sorted by their activity as highly active $\left(++++, \mathrm{EC}_{50} \leq 10 \mathrm{nM}\right)$, moderately active $\left(+++, 10 \mathrm{nM}<\mathrm{EC}_{50} \leq 100 \mathrm{nM}\right)$, least active $\left(++, 100<\mathrm{EC}_{50} \leq\right.$ $1000 \mathrm{nM})$, and inactive $\left(+, \mathrm{EC}_{50}>1000 \mathrm{nM}\right)$. The estimated 


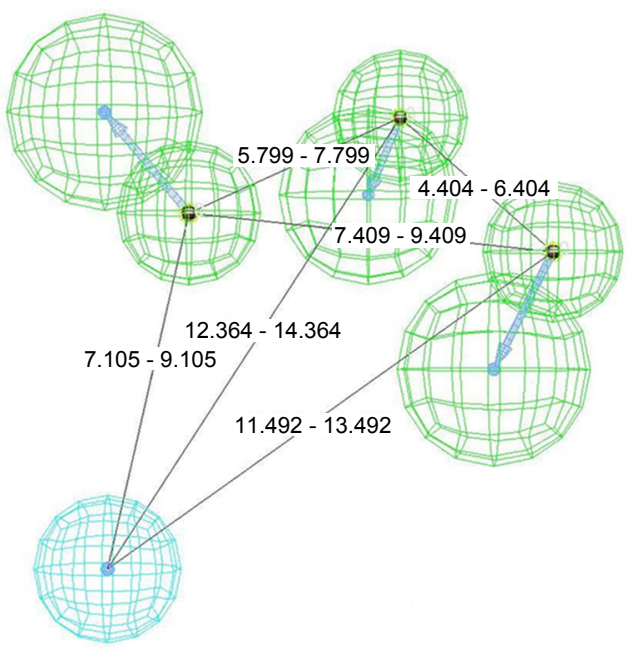

Figure 2. Three-dimentional representation of the best hypothesis (Hypo7). It is comprised with three hydrogen-bond acceptors (green) and one hydrophobic (blue). All distances are represented in $\AA$ unit.

Table 2. Values of training set with experimental and estimated activities

\begin{tabular}{|c|c|c|c|c|c|c|}
\hline Compd & $\begin{array}{l}\text { Actual } \\
\mathrm{EC}_{50} \\
(\mathrm{nM})\end{array}$ & $\begin{array}{c}\text { Estimated } \\
\mathrm{EC}_{50} \\
(\mathrm{nM})\end{array}$ & Error $^{a}$ & $\begin{array}{c}\text { Fit } \\
\text { value }^{b}\end{array}$ & $\begin{array}{l}\text { Activity } \\
\text { scale }^{c}\end{array}$ & $\begin{array}{c}\text { Estimated } \\
\text { activity } \\
\text { scale }^{c}\end{array}$ \\
\hline 1 & 0.1 & 0.19 & +1 & 7.60 & ++++ & ++++ \\
\hline 2 & 0.36 & 0.41 & +1.1 & 6.98 & ++++ & ++++ \\
\hline 3 & 0.54 & 0.36 & -1.8 & 7.11 & ++++ & ++++ \\
\hline 4 & 30 & 96 & +3.2 & 4.62 & +++ & +++ \\
\hline 5 & 51 & 160 & +3.2 & 4.39 & +++ & ++ \\
\hline 6 & 66 & 62 & -1.1 & 4.80 & +++ & +++ \\
\hline 7 & 80 & 28 & -2.8 & 5.15 & +++ & +++ \\
\hline 8 & 80 & 570 & +7.1 & 3.84 & +++ & ++ \\
\hline 9 & 90 & 230 & +2.5 & 4.24 & +++ & ++ \\
\hline 10 & 110 & 640 & +5.8 & 3.79 & ++ & ++ \\
\hline 11 & 160 & 170 & +1 & 4.37 & ++ & ++ \\
\hline 12 & 290 & 320 & +1.1 & 4.10 & ++ & ++ \\
\hline 13 & 300 & 710 & +2.4 & 3.74 & ++ & ++ \\
\hline 14 & 300 & 640 & +2.1 & 3.79 & ++ & ++ \\
\hline 15 & 400 & 320 & -1.3 & 4.09 & ++ & ++ \\
\hline 16 & 500 & 660 & +1.3 & 3.78 & ++ & ++ \\
\hline 17 & 550 & 450 & -1.2 & 3.94 & ++ & ++ \\
\hline 18 & 1100 & 900 & -1.2 & 3.64 & + & ++ \\
\hline 19 & 1356 & 730 & -1.9 & 3.73 & + & ++ \\
\hline 20 & 1400 & 960 & -1.5 & 3.61 & + & ++ \\
\hline 21 & 2000 & 760 & -2.6 & 3.72 & + & + \\
\hline 22 & 2000 & 3100 & +1.6 & 3.10 & + & ++ \\
\hline 23 & 2500 & 750 & -3.3 & 3.72 & + & ++ \\
\hline 24 & 3000 & 850 & -3.5 & 3.67 & + & ++ \\
\hline 25 & 3000 & 720 & -4.2 & 3.74 & + & ++ \\
\hline 26 & 3300 & 830 & -4 & 3.68 & + & ++ \\
\hline
\end{tabular}

${ }^{a_{+}}$indicates that the estimated $\mathrm{EC}_{50}$ is higher than the actual $\mathrm{EC}_{50}$; - indicates that the estimated $\mathrm{EC}_{50}$ is lower than the actual $\mathrm{EC}_{50} ;+1$ indicates that estimated $\mathrm{EC}_{50}$ is equal to the actual $\mathrm{EC}_{50} .{ }^{b} \mathrm{Fit}$ value indicates how well the features in the pharmacophore overlap the chemical features in the molecule. ${ }^{c}$ Activity scale:,$++++ \mathrm{EC}_{50}<10 \mathrm{nM}$ (highly active); +++, $10<\mathrm{EC}_{50} \leq 100 \mathrm{nM}$ (moderately active); ++, $100<\mathrm{EC}_{50} \leq 1000 \mathrm{nM}$ (least active);,$+ \mathrm{EC}_{50}>1000 \mathrm{nM}$ (inactive). (a)

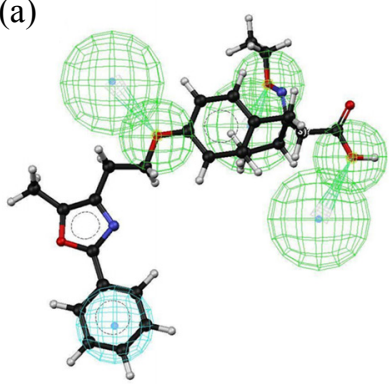

(b)

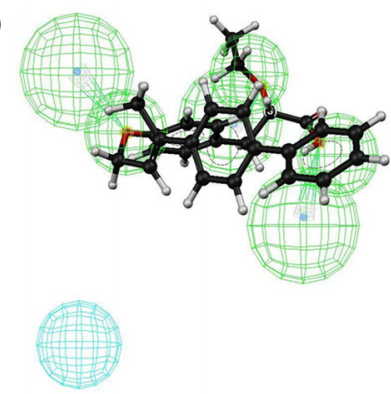

Figure 3. The Hypo7 mapping with training set compound 1 (a) which is the highest active compound and compound 22 (b) which is the lowest active compound about estimated activity. Pharmacophore features which is green for hydrogen-bond acceptor feature (HBA) and blue for hydrophobic (HY).

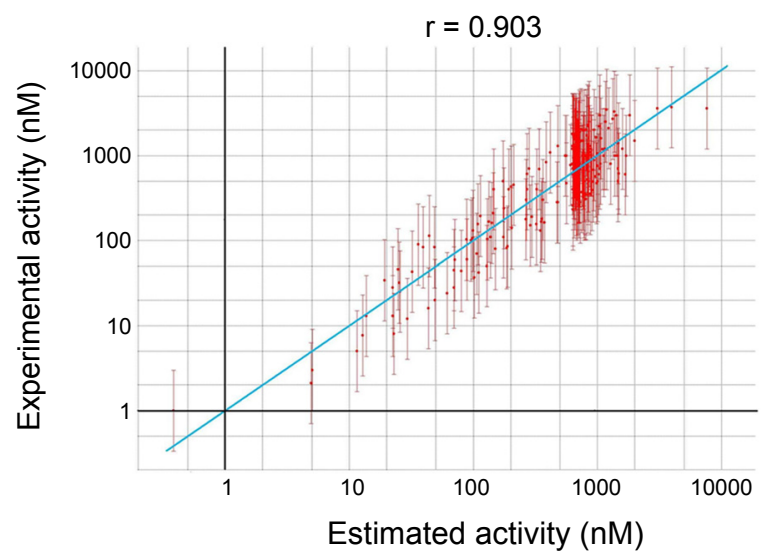

Figure 4. Correlation between actual and calculated activity data over 862 test set compounds.

activities of 26 training set molecules were calculated based on the Hypo7 (Table 2). All highly active and least active compounds were evaluated as same activity level and moderately active compounds were also measured as within the mostly similar range. Although the almost inactive compounds were predicted as least active level, all of the calculated values closed to the inactive level, over $700 \mathrm{nM}$. The analysis of structural mapping comparison was also performed between pharmacophore model and training set considering not only numerical similarity. Therefore, Hypo 7 was aligned with compound 1 $\left(\mathrm{EC}_{50}=0.1 \mathrm{nM}\right.$, fit value $\left.=7.60\right)$ which shows the highest estimated activity and fit value and with compound $22\left(\mathrm{EC}_{50}=\right.$ $3100 \mathrm{nM}$, fit value $=3.10$ ) which is the lowest one among the training set molecules (Fig. 3).

Validation of the Pharmacophore Model by Two Approaches. In order to validate the quality of the Hypo7, test set comparison between estimated activity and experimental data was performed. The test set which composed 862 compounds representing different activity range and structure from the in-house database. The test set conformers were generated by same conformational analysis with applied to the training set. A correlation coefficient of 0.903 between experimental and estimated activity was generated using the test set molecules (Fig. 4) and it indicates that Hypo 7 is convictive model. One of the highest (compound 1) and the lowest (compound 805) active compounds 
(a)

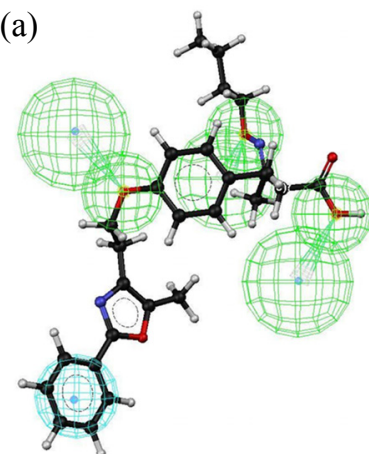

(b)

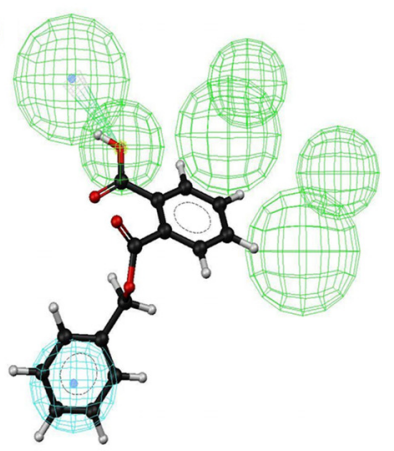

Figure 5. The Hypo 7 mapping with the highest active compound (a) and lowest active compound (b) from the test set.

Table 3. CatScramble cross-validation results

\begin{tabular}{lccc}
\hline \multicolumn{1}{c}{ Validation no. } & Total cost $^{a}$ & $\Delta$ Cost & Correlation (r) \\
\hline Result for unscrambled & & & \\
Hypothesis 7 & 108.297 & 59.715 & 0.941 \\
\hline Results for scrambled & & & \\
Trial 1 & & & \\
Trial 2 & 160.186 & 7.826 & 0.468 \\
Trial 3 & 142.731 & 25.281 & 0.658 \\
Trial 4 & 141.595 & 26.417 & 0.668 \\
Trial 5 & 158.941 & 9.071 & 0.477 \\
Trial 6 & 147.072 & 20.94 & 0.602 \\
Trial 7 & 141.911 & 26.101 & 0.696 \\
Trial 8 & 138.951 & 29.061 & 0.702 \\
Trial 9 & 135.984 & 32.028 & 0.729 \\
Trial 10 & 165.513 & 2.499 & 0.364 \\
Trial 11 & 147.127 & 20.885 & 0.622 \\
Trial 12 & 159.785 & 8.227 & 0.465 \\
Trial 13 & 151.468 & 16.544 & 0.580 \\
Trial 14 & 139.437 & 28.575 & 0.713 \\
Trial 15 & 170.766 & -2.754 & 0.293 \\
Trial 16 & 138.803 & 29.209 & 0.739 \\
Trial 17 & 147.299 & 20.713 & 0.609 \\
Trial 18 & 142.735 & 25.277 & 0.659 \\
Trial 19 & 138.351 & 29.661 & 0.747 \\
Thil cos for & 151.707 & 16.305 & 0.561
\end{tabular}

${ }^{a}$ Null cost for 168.012 bits, fixed cost for 99.086 bits, and configuration cost for 10.507 bits.

of test set are mapping on Hypo7 (Fig. 5). The predicted activities of two molecules were $0.24 \mathrm{nM}$ (actual $\mathrm{EC}_{50}=0.19 \mathrm{nM}$ ), and $4579 \mathrm{nM}$ (actual $\mathrm{EC}_{50}=10,000 \mathrm{nM}$ ), respectively.

Another validation approach was applied by using the CatScramble program based on Fischer randomization test to assess the quality of the Hypo7. The goal of this method is to prove whether there is a strong correlation between the chemical structures and the biological activity. In this test, correlation was measured with randomly scrambled the structures and activities. We chose $95 \%$ confidence level, thus 19 random spreadsheets were generated (Table 3 ) and the correlation should be low for significant validation. Out of the 19 trials, five had a correlation value around 0.7 which a little high level, but all of the $\Delta$ costs (null cost - total cost) were less than 30 values. Therefore, this

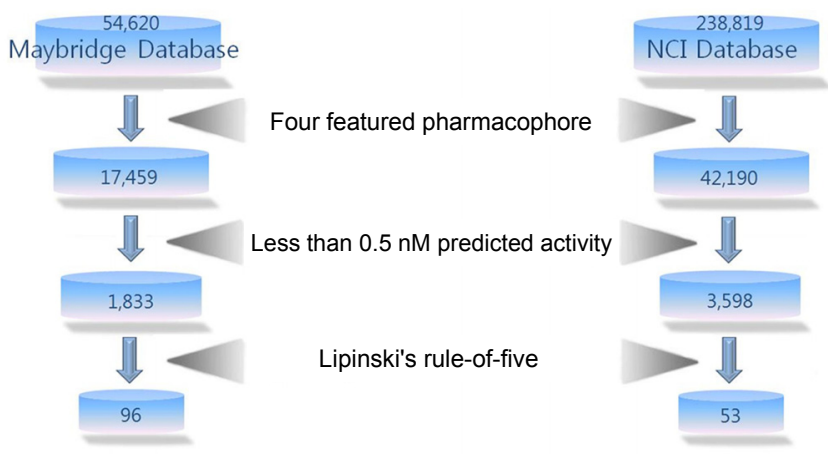

Figure 6. Flowchart of the screening procedure to generate new compounds for PPAR $\gamma$ agonist.

statistic cross validation suggests that the Hypo 7 is not generated by chance and thus has been concluded as meaningful pharmacophore hypothesis.

Database Search. The Hypo 7, validated four feature pharmacophore model was used as a search query to retrieve compounds from chemical databases, the NCI database $(238,819$ compounds) and Maybridge database (54,620 compounds). Based on the 3D query, NCI and Maybridge databases filtered out 42,190 and 17,459 lead compounds, respectively. Their activities were estimated and then consequentially 3,598 in NCI and 1,833 compounds in Maybridge were remained by restricting the minimum estimated activity less than $0.5 \mathrm{nM}$ which is considering the best activity value. After that, the drug-like properties of 5,431 molecules were measured by Lipinski's ruleof-five using Molinspiration online database. ${ }^{38}$ The compounds which satisfy Lipinski's rule $(\log \mathrm{P}<5$, molecular weight $<500$, hydrogen bond donors $<5$, hydrogen bond acceptors $<10$ ) represent with the high oral bioavailability and reduced flexibility (rotatable bonds $<10$ ). ${ }^{39}$ Ultimately the 96 leads from Maybridge and 53 leads from NCI have satisfied the rules among 5,431 compounds and overall series of screening criteria are provided (Fig. 6).

Molecular Docking Studies. All of the 149 lead compounds were docked into PPAR $\gamma$ active site by GOLD docking software to calculate the interacting ability. The fitness score which means overall value of van der Waals and electrostatic interactions is the most important for binding protein. ${ }^{37}$ So we sorted fitness score of top 20 compounds at first and predicted activity, the number of hydrogen bond and the number of non-bonded contact are assistant value of the molecules (Table 4). Top 2 of them which are based on the fitness score and estimated activity were selected as the drug candidate structures, NCI0077416 (74.67 and $0.15 \mathrm{nM}$ ) and HTS09148 (74.30 and $0.25 \mathrm{nM}$ ). The best molecule, NCI0077416, has one hydrogen bond interaction were $3.27 \AA$ with Met364 and 7 hydrophobic contacts. Secondary molecule, HTS09148, has one hydrogen bond interaction were $3.15 \AA$ with $\operatorname{Arg} 288$ and 8 hydrophobic contacts (Fig. 7). Finally, we present the two best candidate structures mapped with Hypo7 (Fig. 8). These two molecules showed the best estimated activity, calculated drug-like properties and binding affinity and thus can be treated as good leads in design of new agonist candidates targeting the PPAR $\gamma$. 
Table 4. Fitness score and the number of interactions of new lead compounds

\begin{tabular}{|c|c|c|c|c|c|c|c|c|}
\hline Molecule name $^{a}$ & Fitness score $^{b}$ & $\begin{array}{l}\text { Estimated activity } \\
(\mathrm{nM})\end{array}$ & $\begin{array}{l}\text { Number of } \\
\text { H-bond }\end{array}$ & $\begin{array}{l}\text { Non-bonded } \\
\text { contact }\end{array}$ & Fit value & Training set & Fitness score & $\begin{array}{c}\text { Estimated } \\
\text { activity }(\mathrm{nM})\end{array}$ \\
\hline NCI0077416 & 74.67 & 0.15 & 1 & 23 & 7.42 & 1 & 76.43 & 0.19 \\
\hline HTS09148 & 74.30 & 0.25 & 1 & 26 & 7.20 & 3 & 68.79 & 0.36 \\
\hline NCI0686579 & 74.20 & 0.14 & 0 & 50 & 7.46 & 4 & 68.50 & 96 \\
\hline JFD03000 & 73.58 & 0.18 & 3 & 31 & 7.34 & 8 & 61.56 & 570 \\
\hline AW01027 & 69.97 & 0.22 & 2 & 34 & 7.25 & 14 & 59.64 & 640 \\
\hline NCI0134155 & 69.90 & 0.21 & 2 & 24 & 7.28 & 15 & 61.12 & 320 \\
\hline HTS02354 & 69.11 & 0.18 & 3 & 31 & 7.35 & 17 & 62.15 & 450 \\
\hline JFD00806 & 69.09 & 0.14 & 0 & 34 & 7.44 & 18 & 49.12 & 900 \\
\hline NCI0694551 & 68.30 & 0.19 & 7 & 40 & 7.32 & 19 & 56.69 & 730 \\
\hline NCI0211882 & 68.02 & 0.17 & 3 & 36 & 7.36 & 21 & 55.81 & 760 \\
\hline NCI0211841 & 66.70 & 0.12 & 1 & 34 & 7.50 & & & \\
\hline AW01154 & 66.62 & 0.17 & 0 & 43 & 7.37 & & & \\
\hline ВТВ04791 & 66.59 & 0.19 & 2 & 32 & 7.33 & & & \\
\hline NCI0160913 & 66.46 & 0.21 & 0 & 33 & 7.28 & & & \\
\hline NCI0211983 & 66.07 & 0.15 & 2 & 31 & 7.42 & & & \\
\hline AW01220 & 65.74 & 0.15 & 0 & 39 & 7.43 & & & \\
\hline HTS01903 & 65.50 & 0.49 & 0 & 34 & 6.90 & & & \\
\hline NCI0160943 & 65.21 & 0.21 & 1 & 29 & 7.45 & & & \\
\hline HTS02436 & 64.68 & 0.14 & 1 & 28 & 7.45 & & & \\
\hline HTS03899 & 63.84 & 0.16 & 2 & 35 & 7.40 & & & \\
\hline
\end{tabular}

${ }^{a}$ Molecules with NCI are from NCI database and the rest molecules are from Maybridge database. ${ }^{b}$ Fitness score signifies how well the active site of target protein is related to the molecules.
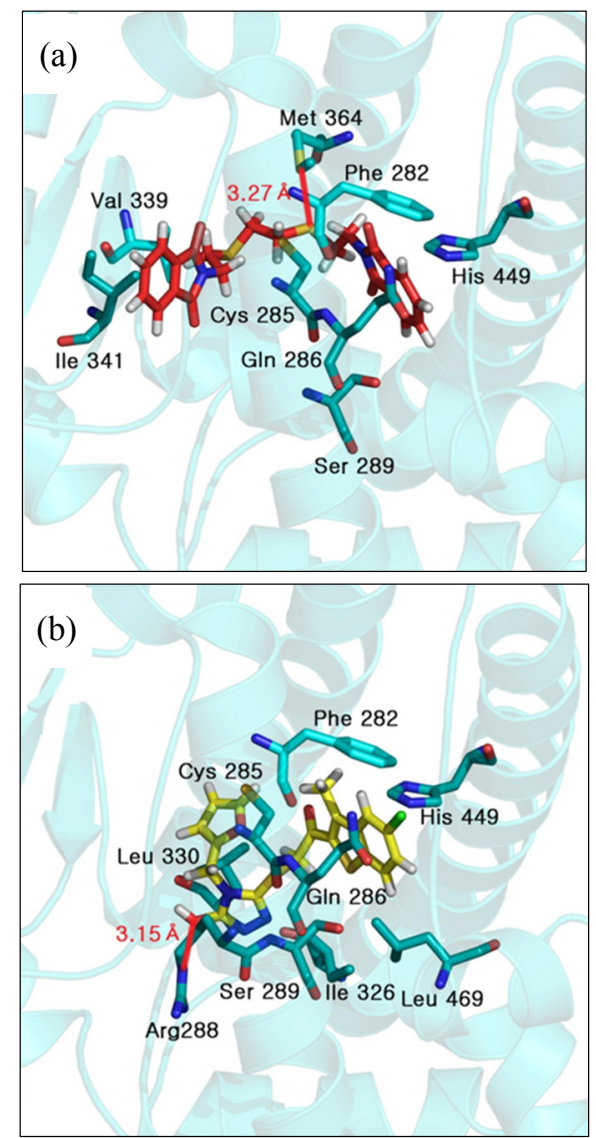

Figure 7. Docking result of new lead compounds; NCI0077416 (a) interacts with Met 364 by hydrogen bond and 7 hydrophobic contacts. HTS09148 (b) has one hydrogen bond with Arg288 and 8 hydrophobic contacts. (a)
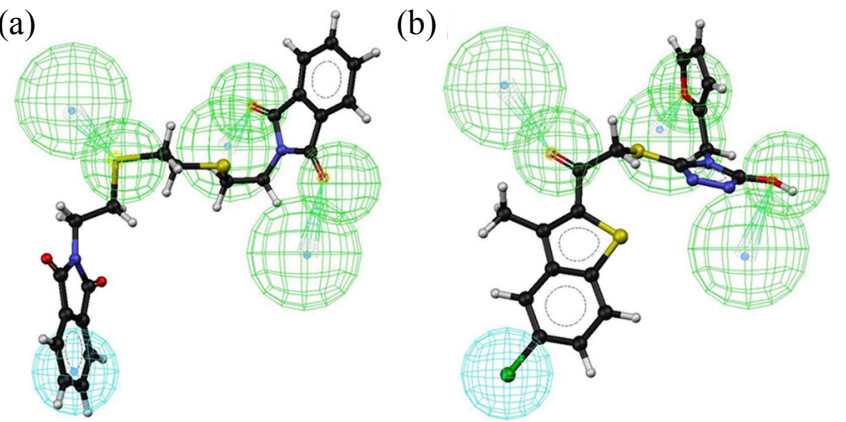

Figure 8. The Hypo7 mapping with new lead compounds NCI0077416 (a) and HTS09148 (b).

\section{Conclusion}

Major goal of this study is to generate a meaningful pharmacophore model that could be applied as a query tool to search 3D databases and screen them based on drug-like compounds to discover new lead molecules for PPAR $\gamma$ agonist. A highly reliable pharmacophore model, consist of three HBAs and one HY, Hypo 7 was generated by training set of 26 structures and identified by the correlation coefficient of 0.941 . The model was well validated by two methods: one using the test set of 862 molecules and CatScramble method.

New lead compounds were obtained by validated pharmacophore model. From the NCI database and Maybridge database, 42,190 and 17,459 structures were used for screening the model, respectively. The number of candidates was reduced to 3,598 (NCI) and 1,833 (Maybridge) when predicted activity was considered less than $0.5 \mathrm{nM}$. Lipinski's rule-of-five for deter- 
mine drug-like properties filtrated the new lead compounds and so finally 53 molecules from NCI and 96 molecules from Maybridge were obtained. Molecular docking which plays crucial role to eliminate inappropriate compounds was used for selecting the best two candidates. Thus, Hypo 7 can be helpful to find new chemical entities with potent activity against a target as well as desired physiological properties through 3D database search.

Acknowledgments. This research was supported by Basic Science Research Program (2009-0073267) and Pioneer Research Center Program (2009-0081539) through the National Research Foundation of Korea (NRF) funded by the Ministry of Education, Science and Technology (MEST). And all students were recipient of fellowship from the BK21 Program of MEST.

\section{References}

1. Gearing, K. L.; Göttlicher, M.; Teboul, M.; Widmark, E.; Gustafsson, J. A. Proc. Natl. Acad. Sci. USA 1993, 90, 1440.

2. Issemann, I.; Prince, R. A.; Tugwood, J. D.; Green, S. J. Mol. Endocrinol. 1993, 11, 37.

3. Desvergne, B.; Wahli, W. Endocr. Rev. 1999, 20, 649.

4. Bardot, O.; Aldridge, T. C.; Latruffe, N.; Green, S. Biochem. Biophys. Res. Commun. 1993, 192, 37.

5. Feige, J. N.; Gelman, L.; Michalik, L.; Desvergne, B.; Wahli, W. Prog. Lipid. Res. 2006, 45, 120.

6. Gurnell, M. Clin. Endocrinol. 2003, 59, 267.

7. Renaud, J. P.; Moras, D. Cell. Mol. Life. Sci. 2000, 57, 1748

8. Voutsadakis, I. A. J. Cancer. Res. Clin. Oncol. 2007, 133, 917.

9. Fajas, L.; Auboeuf, D.; Raspé, E.; Schoonjans, K.; Lefebvre, A. M.; Saladin, R.; Najib, J.; Laville, M,; Fruchart, J. C.; Deeb, S.; VidalPuig, A.; Flier, J.; Briggs, M. R.; Staels, B.; Vidal, H.; Auwerx, J. J. Biol. Chem. 1997, 272, 18779.

10. Chen, Y.; Jimenez, A. R.; Medh, J. D. Biochim. Biophys. Acta 2006, $1759,32$.

11. Elbrecht, A.; Chen, Y.; Cullinan, C. A.; Hayes, N.; Leibowitz, M.; Moller, D. E.; Berger, J. Biochem. Biophys. Res. Commun. 1996, $224,431$.

12. Hara, K.; Okada, T.; Tobe, K.; Yasuda, K.; Mori, Y.; Kadowaki, H.; Hagura, R.; Akanuma, Y.; Kimura, S.; Ito, C.; Kadowaki, T. Biochem. Biophys. Res. Commun. 2000, 271, 212.

13. Nomura, M.; Tanase, T.; Ide, T.; Tsunoda, M.; Suzuki, M.; Uchiki, H.; Murakami, K.; Miyachi, H. J. Med. Chem. 2003, 46, 3581.

14. Koyama, H.; Boueres, J. K.; Han, W.; Metzger, E. J.; Bergman, J. P.; Gratale, D. F.; Miller, D. J.; Tolman, R. L.; MacNaul, K. L.; Berger, J. P.; Doebber, T. W.; Leung, K.; Moller, D. E.; Heck, J. V.; Sahoo, S. P. Bioorg. Med. Chem. Lett. 2003, 13, 1801.

15. Koyama, H.; Boueres, J. K.; Miller, D. J.; Berger, J. P.; MacNaul, K. L.; Wang, P. R.; Ippolito, M. C.; Wright, S. D.; Agrawal, A. K.; Moller, D. E.; Sahoo, S. P. Bioorg. Med. Chem. Lett. 2005, 15, 3347.

16. Kim, N. J.; Lee, K. O.; Koo, B. W.; Li, F.; Yoo, J. K.; Park, H. J.; Min, K. H.; Lim, J. I.; Kim, M. K.; Kim, J. K.; Suh, Y. G. Bioorg. Med. Chem. Lett. 2007, 17, 3595.

17. Sauerberg, P.; Bury, P. S.; Mogensen, J. P.; Deussen, H. J.; Pettersson, I.; Fleckner, J.; Nehlin, J.; Frederiksen, K. S.; Albrektsen, T.; Din, N.; Svensson, L. A.; Ynddal, L.; Wulff, E. M.; Jeppesen, L. J. Med. Chem. 2003, 46, 4883 .

18. Casimiro-Garcia, A.; Bigge, C. F.; Davis, J. A.; Padalino, T.; Pulaski, J.; Ohren, J. F.; McConnell, P.; Kane, C. D.; Royer, L. J.;
Stevens, K. A.; Auerbach, B. J.; Collard, W. T.; McGregor, C.; Fakhoury, S. A.; Schaum, R. P.; Zhou, H. Bioorg. Med. Chem. 2008, 16, 4883.

19. Mahindroo, N.; Wang, C. C.; Liao, C. C.; Huang, C. F.; Lu, I. L.; Lien, T. W.; Peng, Y. H.; Huang, W. J.; Lin, Y. T.; Hsu, M. C.; Lin, C. H.; Tsai, C. H.; Hsu, J. T.; Chen, X.; Lyu, P. C.; Chao, Y. S.; Wu, S. Y.; Hsieh, H. P. J. Med. Chem. 2006, 49, 1212.

20. Mahindroo, N.; Huang, C. F.; Peng, Y. H.; Wang, C. C.; Liao, C. C.; Lien, T. W.; Chittimalla, S. K.; Huang, W. J.; Chai, C. H.; Prakash, E.; Chen, C. P.; Hsu, T. A.; Peng, C. H.; Lu, I. L.; Lee, L. H.; Chang, Y. W.; Chen, W. C.; Chou, Y. C.; Chen, C. T.; Goparaju, C. M.; Chen, Y. S.; Lan, S. J.; Yu, M. C.; Chen, X.; Chao, Y. S.; Wu, S. Y.; Hsieh, H. P. J. Med. Chem. 2005, 48, 8194.

21. Koyama, H.; Miller, D. J.; Boueres, J. K.; Desai, R. C.; Jones, A. B.; Berger, J. P.; MacNaul, K. L.; Kelly, L. J.; Doebber, T. W.; Wu, M. S.; Zhou, G.; Wang, P. R.; Ippolito, M. C.; Chao, Y. S.; Agrawal, A. K.; Franklin, R.; Heck, J. V.; Wright, S. D.; Moller, D. E.; Sahoo, S. P. J. Med. Chem. 2004, 47, 3255.

22. Liu, K.; Xu, L.; Berger, J. P.; Macnaul, K. L.; Zhou, G.; Doebber, T. W.; Forrest, M. J.; Moller, D. E.; Jones, A. B. J. Med. Chem. 2005, 48, 2262.

23. Willson, T. M.; Brown, P. J.; Sternbach, D. D.; Henke, B. R. J. Med. Chem. 2000, 43, 527.

24. Li, Z.; Liao, C.; Ko, B. C.; Shan, S.; Tong, E. H.; Yin, Z.; Pan, D.; Wong, V. K.; Shi, L.; Ning. Z. Q.; Hu, W.; Zhou, J.; Chung, S. S.; Lu, X. P. Bioorg. Med. Chem. Lett. 2004, 14, 3507.

25. Mogensen, J. P.; Jeppesen, L.; Bury, P. S.; Pettersson, I.; Fleckner, J.; Nehlin, J.; Frederiksen, K. S.; Albrektsen, T.; Din, N.; Mortensen, S. B.; Svensson, L. A.; Wassermann, K.; Wulff, E.M.; Ynddal, L.; Sauerberg, P. Bioorg. Med. Chem. Lett. 2003, 13, 257.

26. Thor, M.; Beierlein, K.; Dykes, G.; Gustavsson, A. L.; Heidrich, J.; Jendeberg, L.; Lindqvist, B.; Pegurier, C.; Roussel, P.; Slater, M.; Svensson, S.; Sydow-Bäckman, M.; Thornström, U.; Uppenberg, J. Bioorg. Med. Chem. Lett. 2002, 12, 3565.

27. Sauerberg, P.; Mogensen, J. P.; Jeppesen, L.; Bury, P. S.; Fleckner, J.; Olsen, G. S.; Jeppesen, C. B.; Wulff, E. M.; Pihera, P.; Havranek, M.; Polivka, Z.; Pettersson, I. Bioorg. Med. Chem. Lett. 2007, 17, 3198.

28. Desai, R. C.; Gratale, D. F.; Han, W.; Koyama, H.; Metzger, E.; Lombardo, V. K.; MacNaul, K. L.; Doebber, T. W.; Berger, J. P.; Leung, K.; Franklin, R.; Moller, D. E.; Heck, J. V.; Sahoo, S. P. Bioorg. Med. Chem. Lett. 2003, 13, 3541.

29. Caijo, F.; Mosset, P.; Grée, R.; Audinot-Bouchez, V.; Boutin, J.; Renard, P.; Caignard, D. H.; Dacquet, C. Bioorg. Med. Chem. Lett. 2005, 15, 4421 .

30. Han, H. O.; Kim, S. H.; Kim, K. H.; Hur, G. C.; Yim, H. J.; Chung, H. K.; Woo, S. H.; Koo, K. D.; Lee, C. S.; Koh, J. S.; Kim, G. T. Bioorg. Med. Chem. Lett. 2007, 17, 937.

31. Bharatham, K.; Bharatham, N.; Lee, K. W. Arch. Pharm. Res. 2007, $30,533$.

32. Lee, Y.; Bharatham, N.; Bharatham, K.; Lee, K. W. Bull. Korean. Chem. Soc. 2007, 28, 561 .

33. CATALYST 4.10; Accelrys, Inc., San Diego, CA, 2005, http:// www.accelrys.com.

34. Du, L. P.; Li, M. Y.; Tsai, K. C.; You, Q. D.; Xia, L. Biochem. Biophys. Res. Commun. 2007, 322, 677.

35. Bharatham, N.; Bharatham, K.; Lee, K. W. J. Mol. Graph. Model. 2007, 25, 813 .

36. Bharatham, N.; Bharatham, K.; Lee, K. W. Bull. Korean. Chem. Soc. 2007, 28, 200.

37. Tetko, I. V. Mini. Rev. Med. Chem. 2003, 3, 809.

38. Lipinski, C. A.; Lombardo, F.; Dominy, B. W.; Feeney, P. J. Adv. Drug. Deliv. Rev. 2001, 46, 3 .

39. Jones, G.; Willett, P.; Glen, R. C.; Leach, A. R.; Taylor, R. J. Mol. Biol. 1997, 267, 727. 